\title{
En su propia voz: ser periodista mujer en Guadalajara
}

\author{
From her own voice: What to be a female journalist in \\ Guadalajara means
}

\author{
Elvira Laura Hernández Carballido \\ elviracarballido62@gmail.com \\ Universidad Autónoma del Estado de Hidalgo, \\ México \\ https://orcid.org/0000-0003-2733-9904
}

Hernández Carballido, E. L. (2021). En su propia voz: ser periodista mujer en Guadalajara. Oralidad-es, 7, 1-16. https://doi.org/10.53534/oralidad-es.v7a3

Fecha de recepción: 22 de julio de 2021 / Fecha de aceptación: 11 de noviembre de 2021 


\section{Abstract}

This article shows eight Guadalajara female journalists describing her work from their inner voices that emerged from interviews published early in 2018. By using the Mexican Journalism Research Association methodology (AMIC), three targeted aspects were analyzed: What being a journalist is like, the journalist working hours, and the meaning of female journalist self-recognition. By examining the eight interviews, attention was given to the female journalists 'voices, their understanding of their own opportunities to reshape their professional role, the use of colloquial language, their private and public spaces, and what being a journalist is and should be.

\section{Keywords}

Gender, oral, female journalist, journalism, sexual roles.

\section{Resumen}

El objetivo es describir desde su propia voz la situación de las mujeres periodistas en la ciudad de Guadalajara. Se eligieron siete entrevistas publicadas en 2018 a reporteras de la entidad. Para ello, se aplicaron metodologías propuestas en el grupo de Estudios de Periodismo de la Asociación Mexicana de Investigadores de la Comunicación (AMIC) y se retomaron tres puntos básicos: Ser periodista, la jornada de trabajo y el significado de reconocerse mujeres periodistas. La oralidad en este ejercicio fue una herramienta útil para los fines antropológicos de género, las entrevistadas detallaron desde sus propias expresiones las posibilidades de transformar su rol asignado, enmarcaron en su lenguaje coloquial lo privado y lo público, así como las diferencias entre el ser y el deber ser.

\section{Palabras Clave}

Género; oralidad; mujer periodista; periodismo; rol sexual. 


\section{Introducción}

El objetivo de este trabajo es recuperar en la propia voz de mujeres periodistas la forma en que han vivido su labor y distinguir si han enfrentado alguna situación de desigualdad o discriminación por razones de género. La investigación parte de la pregunta: ¿Qué significa para las periodistas de la ciudad de Guadalajara ser mujeres que ejercen esta profesión en su entidad?

En los estudios de periodismo realizados en México todavía pocos han abordado la presencia de las mujeres en este oficio y el panorama se reduce cuando el tema se delimita a una región del país.

De igual manera, los de oralidad no han desarrollado una línea específica sobre las expresiones particulares de las mujeres y la importancia de sus testimonios compartidos a través de entrevistas. Sin embargo, las investigaciones existentes, reconocen lo significativo de aprovechar más el género y la oralidad:

La Historia Oral es una herramienta metodológica especialmente útil para los fines de la Antropología de Género, pues a través de ella se recupera la palabra de las mujeres, su voz, sus vivencias, sus pensamientos y sus deseos. La palabra como expresión, como comunicación y como forma de impulsar un cambio en la situación y condición de las mujeres. Sin embargo, el eje de género ha sido poco estudiado. Se necesita un método, una teoría, una voluntad y una conciencia para aplicarlo, no se da de forma espontánea al hablar de las mujeres. Por eso los datos recogidos desde la perspectiva de género resultan sumamente valiosos para reconstruir la vida de las mujeres y de los hombres desde otra mirada, y enriquecer el acervo teórico de la Antropología de género, así como de la Historia Oral. (Alberti, 7)
Es así como un grupo representativo de investigadoras sostiene que la Historia Oral puede ayudar de manera fundamental a reconstruir la identidad de las mujeres, del género femenino, a través de sus testimonios compartidos en entrevistas y charlas, una herramienta útil en la construcción de la teoría del género, ya que permite que las entrevistadas desde su propia experiencia compartan la manera en que han aceptado o cuestionado el rol asignado.

Fue de esa manera que, debido a una estancia académica que se realizó en la Universidad de Guadalajara en 2015, se trabajó el tema y se decidió recuperar en voz de las mismas reporteras del estado de Jalisco. Para ello se revisaron las preguntas aplicadas en investigaciones ${ }^{1}$ que recuperan las rutinas y experiencias de periodistas en México, y se retomaron las tres que podían guiar este texto:

1. Por qué son periodistas.

2. La rutina laboral en sus periódicos.

3. El significado de ser mujer periodista.

La Universidad de Guadalajara y el Instituto Tecnológico de Estudios de Occidente (ITESO), principalmente, tienen sus áreas de estudio en comunicación -con especializaciones en periodismo- donde sus intereses y perspectivas se han centrado en una gran variedad de cuestiones representativas de este campo académico, pero los trabajos en torno a las mujeres periodistas que hablan sobre su propia experiencia parecen no estar todavía muy desarrollados.

\footnotetext{
${ }^{1}$ Los estudios consultados son: Salvador de León Vázquez. “El empleo en los medios de comunicación. Situación de ocupación de los comunicadores en Aguascalientes” 2007) y “Prácticas periodísticas en Aguascalientes: estructuras de interpretación para acercarse al acontecer" (2004). Mireya Márquez. "Panorama de los perfiles demográficos, laborales y profesionales de. los periodistas en México" (2017) y Valores normativos y prácticas de reporteo en tensión: percepciones profesionales de periodistas en México (2012). Alma Gutiérrez Leyton. "Procesos de autocensura y subjetividad en el trabajo periodístico en contextos de violencia y narcotráfico en Nuevo León (2016).
} 
Es así como en una búsqueda sobre artículos, libros o tesis que, en el campo de la comunicación, que hagan referencia al tema, únicamente se encontró una sola referencia que abordaba de manera concreta y delimitada el tema, es la tesis de Laura Tatiana Herrero Morales y Orozco (1991). A su juicio, hay tres momentos representativos de las mujeres en los escenarios periodísticos de Jalisco:

1. Antecedentes de la mujer en la prensa tapatía. Mitad del siglo XIX hasta la primera década del siglo XX.

\section{Las informadoras. El Informador es el} diario más longevo del estado, apareció en 1917, y desde sus primeros números algunas mujeres escribieron en sus páginas.

3. Reporteras. De 1988 a 1991 el número de mujeres se triplicó en la prensa Guadalajara y al terminar el siglo XX ya cubren todas las fuentes.

Además de la tesis mencionada, no se encontró un trabajo parecido o relacionado al tema en el ámbito de los estudios de la comunicación y/o el periodismo, ni de la oralidad. Si bien, hay trabajos de investigación muy significativos sobre los medios de comunicación en Jalisco, donde se analiza desde sus relaciones con el poder, la forma en que han abordados noticias en momentos significativos, las condiciones laborales, la historia de la prensa, el análisis del discurso periodístico, la trayectoria de sus publicaciones periodísticas, la presencia femenina se pierde en esos enfoques.

Quienes han recuperado a las mujeres de Jalisco son las historiadoras y en sus investigaciones hay tres tendencias representativas:

1. Recuperan historias femeninas y se destaca la trayectoria de esa mujer, entre cuyas actividades puede estar el periodismo.
2. Se trata de trabajos que utilizan al periódico como fuente de consulta para reconstruir momentos del pasado.

3. Estudios ubicados que recuperan a las mujeres periodistas a través de biografías o semblanzas.

Sus trabajos han permitido advertir que al hacer referencia de las periodistas en el estado podemos distribuirlas en periodos específicos:

1. El siglo XIX. Fue un escenario para que las poetas y narradoras encontraran espacios para publicar sus creaciones literarias.

2. México Independiente y Revolucionario. Surgieron personalidades femeninas que encontraron en la prensa una tribuna para difundir su postura e ideología.

3. Postrevolución. En 1917 el periódico El Informador marcará la pauta del periodismo empresarial y desde sus primeros meses dará espacio a mujeres.

4. Primera mitad del siglo XX. El surgimiento de más publicaciones dará paso a un número muy nutrido de mujeres a colaborar formalmente en la prensa y a reportear.

5. Estudiar periodismo. Las universidades comienzan a abrir sus licenciaturas en periodismo o comunicación, empiezan a llegar las primeras egresadas.

6. Personalidades femeninas en la prensa. La presencia femenina va en aumento en la búsqueda de la noticia, pero no en los puestos de decisión.

7. Siglo XXI. Mujeres que en las primeras décadas de esta época están consolidando una trayectoria en el mundo periodístico de la entidad. 
Es así como el presente texto recupera las voces de siete periodistas de Guadalajara quienes compartieron su experiencia como periodistas y a través de su testimonio puede advertirse su vida profesional y las cuestiones que pueden enfrentar por razones de género.

\section{Referentes conceptuales}

Antes de terminar el siglo XX y en las primeras décadas del XXI han surgido algunos trabajos ${ }^{2}$ más que presentan el panorama del periodismo y la participación de las mujeres mexicanas, destacando las siguientes aportaciones:

1. Coinciden en recuperar a las mujeres que han hecho periodismo para demostrar que se trata de un oficio al que se pudo llegar después que los hombres pero que no les resultaba ajeno a ellas. El objetivo de hacerlas visibles en la historia del periodismo hace posible advertir una forma específica de las mujeres para practicar el ejercicio periodístico.

2. Reconocen la época en que acceden al periodismo de información general, donde se integran a la agenda de su medio y cubren los sucesos noticiosos. Sin embargo, algunas de ellas, además de cumplir con la fuente asignada por su diario, no dejaban de cumplir con su rol tradicional y vivir una doble jornada laboral o sufrir de algún tipo de acoso y discriminación.

3. Pueden reconocer los temas, los géneros periodísticos y la fuente asignada que las mujeres han trabajado en los últimos años, algunas veces en un ambiente donde la equidad de género no es representativa.
Dentro de estos trabajos existe un verdadero esfuerzo por construir un marco teórico que logre dar solidez a sus investigaciones. Es así como, la categoría género es representativa en este trabajo, la cual definimos de acuerdo a Joan Scott (1990):

- Representa una categoría social impuesta sobre un cuerpo sexuado.

- Es un elemento constitutivo de las relaciones sociales basadas en las diferencias que distinguen a los sexos.

- Distingue una forma primaria de las relaciones significantes de poder entre ellos.

La autora propone cuatro elementos interrelacionados que construyen el género en la sociedad:

- Mitos y símbolos. Representaciones que crean estereotipos o un deber ser.

- Conceptos normativos. Aspectos que hacen creer que los mitos son producto de consensos sociales.

- Nociones políticas y referencias a las instituciones y organizaciones sociales. Se considera a la familia, la escuela, la religión y los medios de comunicación, los cuales también influyen en la construcción del género.

- La identidad subjetiva. La manera en que se determina en cada personalidad un rol genérico.

Estos cuatro puntos, asegura Scott, operan conjuntamente y son significativos para comprender cómo lo que empezó como una diferencia sexual biológica se fue convirtiendo en una desigualdad

\footnotetext{
${ }^{2}$ Los trabajos que considero más representativos por el tema los clasifico en dos: 1 . Los realizados por investigadoras y periodistas en España, que son los más consultados por quien escribe este trabajo; y, 2. Los estudios realizados en el contexto nacional. Es así como se han tomado como referencia: Lovera, S. (1991). Las periodistas frente a la problemática femenina, Facultad de Estudios Superiores Acatlán; Amado, A. B. Hiriart y N. Valle, N. (1996). El abc de un periodismo no sexista, Fempress; Bach, M. (2000). El sexo de la noticia, Icaria; Gallego, J. (2002). La prensa por dentro, Editorial Amelia Romero. Güereca, R. (2019). Mujeres, conocimiento y poder. Genealogía vindicativa en los medios de comunicación y las academias, Universidad Autónoma Metropolitana.
} 
social que impone la mayoría de las veces considerar al hombre superior a la mujer. Reconocer esta postura permite revisar el panorama elegido con una mirada diferente.

La perspectiva de género permite enfocar, analizar y comprender las características que definen a mujeres y hombres de manera específica, tanto sus semejanzas como sus diferencias. Desde esa perspectiva se analizan las posibilidades vitales de ellas, pero también de ellos, el sentido de sus vidas, sus expectativas $y$ oportunidades, las complejas y diversas relaciones sociales que se dan entre ambos géneros; asi como los conflictos institucionales $y$ cotidianos que deben encarar, y las múltiples maneras en que lo hacen. Contabilizar los recursos y la capacidad de acción de mujeres $y$ hombres para enfrentar las dificultades de la vida y realizar sus propósitos, es uno de los objetivos de ubicarse en la perspectiva de género, y uno de sus resultados más prometedores. (Cazés, 1998, p. 36)

Los estudios de oralidad con perspectiva de género considero que están en una etapa de exploración y fortalecimiento, pero pueden reconocerse aportaciones y retos:

... se parte de unos principios teóricos entre los cuales se considera a las mujeres como sujetos activos, pensantes, valorando sus hechos y dichos. Con esta base de partida el tipo de preguntas tratarán de rescatar, sobre todo, las vivencias que las mujeres no expresan porque se considera que tienen poco valor. Trabajos pioneros en América Latina en esta linea han sido los de Margaret Randall, en los años setenta con su obra "Mujeres en revolución"(1970), "Todas estamos despiertas" (1984) o "Somos millones (1978). También Moema Viezzer con su famosa obra "Si me permiten hablar" (1977) son algunos ejemplos. Se trata de testimonios de mujeres en situaciones de conflicto como periodos revolucionarios, laborales y politicos, donde se mostraba a las mujeres comprometidas con causas de diversa indole. (Alberti, 1996, p.8)

\section{Metodología}

El punto de partida para este trabajo fue la propuesta de Gabriela Cano y Verena Radku en su investigación titulada Lo privado y lo público o la mutación de espacios. Historia de Mujeres 1920 - 1940 (1986). Ellas consideraron las siguientes etapas de vida para presentar la historia de vida de las mujeres elegidas para su investigación: la infancia, los estudios, la experiencia laboral, la presencia masculina, la maternidad, el movimiento revolucionario, el periodismo, la lucha por las mujeres y la muerte.

Por su parte, Laura Tatiana Herrero Morales y Orozco (1991), al recuperar a las periodistas de Guadalajara se auxilió de la entrevista como técnica principal para recuperar los testimonios de las periodistas y los puntos básicos que dieron pie a la conversación fueron: Opinión de la familia, la combinación trabajo/vida de pareja/ matrimonio/maternidad, problemas a los que se enfrenta la mujer en el desempeño del trabajo periodístico, las relaciones con los compañeros, la forma de convivir con sus compañeras, el reconocimiento que recibe su trabajo, los temas o espacios propios de las mujeres y la importancia del trabajo periodístico para la mujer que es reportera.

Se recurrió a los estudios de periodismo que han dado a conocer las rutinas y experiencias personales del trabajo periodístico en México, donde la entrevista ha sido clave para que los testimonios permitan describir e interpretar las rutinas y compromisos de cada periodista. Entre dichos trabajos destacan los ya citados presentados por De León Vázquez, Márquez Ramírez y Gutiérrez Leyton, quienes a través de la entrevista han recuperado el contexto de la labor periodística 
nacional. Luego de revisar sus cuestionarios y preguntas base de los mismos, retomamos tres que fueron constantes y significativas para el contexto e interpretación de sus datos: Por qué son periodistas, cómo es la rutina laboral en sus periódicos y el significado de ser (mujer) periodista.

En tanto, el binomio oralidad y perspectiva de género fue retomado de Alberti (1996) quien identificó algunas pautas y de las cuales retomamos tres:

1. El cambio. Es la característica más repetida al escudriñar los testimonios de mujeres, quienes en sus historias van advirtiendo que su iniciativa fue determinante para salir de lugares y situaciones con las que no estaban de acuerdo.

\section{Lo público y lo privado. A través de} su lenguaje coloquial, el suceso se enmarca en el ambiente cotidiana, lo público se entremezcla con lo privado al expresar preocupaciones domésticas con las profesionales.

\section{Diferencia entre el Deber Ser y el}

Ser. Los testimonios de mujeres delataban esa constante preocupación en ubicarse dentro de la construcción de género y el significado de advertir que la subjetividad rompía con los roles y actitudes que esperaban tradicionalmente de ellas, asignados por el sistema patriarcal.

Es así como se retomaron esas propuestas para revisar las charlas llevadas a cabo con las periodistas elegidas. En la selección de sus perfiles fue determinante la doctora María Elena Hernández Ramírez, especialista en estudios de periodismo en Jalisco, quien, durante la estancia realizada en la Universidad de Guadalajara, estableció lo que era significativo para seleccionarlas: su trayectoria, el reconocimiento público y una caracterís- tica representativa que destacara su profesionalismo tanto por los temas abordados y el género periodístico utilizado o su pionerismo en alguna actividad. Fue así como las elegidas fueron:

- Rosario Bareño. Primera jefa de información en Jalisco.

- Daniela Geomar. Pionera en el periodismo deportivo en la entidad tapatía.

- Laura Castro Golarte. Fundadora de la página cultural en El Informador.

- Priscilla Hernández. La más joven periodista con reconocimientos internacionales.

- Vanesa Robles. Cronista de gran reconocimiento en Jalisco y representativos premios.

- Esperanza Romero. Periodista de denuncia muy respetada en el estado.

- Yolanda Zamora. Lleva más de treinta años como titular del primer noticiario cultural de la región.

El cuestionario que apoyó cada entrevista realizada giró en torno a siete puntos: 1) Su decisión de ser periodista; 2) El género periodístico que dominan; 3) La fuente informativa asignada; 4) Su forma de trabajo; 5) El ambiente laboral; 6) El salario que perciben; y, 7) Los problemas que enfrentan para realizar su labor.

En la revisión de las entrevistas publicadas fueron seleccionados los fragmentos donde ellas hicieran referencia a estos tres puntos: Por qué son periodistas, Rutina laboral en sus periódicos y Ser mujer periodista.

Finalmente, auxiliándonos en los estudios de género determinamos la importancia de la construcción de esta categoría en su desarrollo periodístico basándonos en las respuestas expresadas durante las entrevistas revisadas. 


\section{Resultados}

Las siete periodistas consultadas especifican la manera en que decidieron ser periodistas, todas hicieron estudios universitarios y advirtieron su facilidad para escribir, así como su interés en informar sobre los sucesos ocurridos en los escenarios sociales para convertirlos en noticia.

Cuadro 1.

Por qué son periodistas.
Su testimonio permite advertir que el cambio es una constante en su vida, pues rompen con sus acciones con el deber ser y apuestan por el ser que late en su vocación que descubrieron desde pequeñas y que se reafirmó al dedicarse al periodismo.

\begin{tabular}{|c|c|}
\hline Periodista & Testimonio \\
\hline Rosario Bareño & $\begin{array}{l}\text { Poco a poco comprobé que se me facilitaba escribir, me encantaba investigar, } \\
\text { averiguar sobre la cuestión social. Casi siempre trabajo la nota. Empecécu- } \\
\text { briendo asistenciales, pero ya tengo muchos años cubriendo politica, que es otro } \\
\text { de mis fuertes, la grilla me encanta. Mi preferida fue la fuente Legislativa, ahí } \\
\text { cae todo lo que pasa en todos lados tanto en la parte del Gobierno como en el } \\
\text { sector privado, es una fuente muy padre. }\end{array}$ \\
\hline Daniela Geomar & $\begin{array}{l}\text { Desde muy pequeña, además de los programas infantiles, me llamaban ya mu- } \\
\text { cho la atención los noticiarios. Primero me asignaron deportes, aunque ahora } \\
\text { soy politica, nunca he dejado de ser periodista. Para entrevistar yo siempre me } \\
\text { preparaba, no me gustaba preguntar tonterías, sobre todo en deportes. Entrevis- } \\
\text { taba, investigaba y sabia qué preguntar. }\end{array}$ \\
\hline Laura Castro & $\begin{array}{l}\text { Soy periodista porque creo que el periodismo es "tribunal de la opinión pública } \\
\text { y retoma las nociones de opinión común como presión social y busca la difu- } \\
\text { sión regular de todas las actividades gubernamentales como un seguro contra } \\
\text { los abusos de poder, aun cuando no siempre funcione. Fui corresponsal en la } \\
\text { ciudad de México y reportera de temas especiales. El reportaje es mi género } \\
\text { favorito, aunque también la entrevista y la crónica. }\end{array}$ \\
\hline Priscila Hernández & $\begin{array}{l}\text { Mi profesor, José Manuel Jurado Parra, me preguntó qué me gustaba hacer: me } \\
\text { gusta contar historias, le dije. Muy bien, desde hoy me vas a hacer narracio- } \\
\text { nes relacionadas con la materia de mi clase. Asi empecé a darle textos. Un día } \\
\text { llegó y me dice: ¡te publiqué! No lo podía creer, me emocioné mucho y entonces } \\
\text { empecé a llevarle más textos. Un día me dijo: No, tú traes mucha energía, mejor } \\
\text { te voy a hacer una cita para que escribas en un periódico. Así fue como a los } 15 \\
\text { años me convertí en reportera. Me ha gustado mucho hacer reportajes y cubrir } \\
\text { temas de interés social, principalmente derechos humanos. }\end{array}$ \\
\hline Vanesa Robles & $\begin{array}{l}\text { Yo entré al periodismo segura de poder darle voz a la gente. Yo hago mis cróni- } \\
\text { cas siempre viendo lo que otros no ven, yo no soy el centro de la historia, es la } \\
\text { gente. Hay tantas historias que recuperar, y esa situación es lo que me inspira } \\
\text { contar un montón de historias, busco el sentido humano. No me doy por venci- } \\
\text { da, soy una necia ingenua, una periodista por vocación y sigo en esto. Escribo } \\
\text { sin miedo, no he sido amenazada, ni perseguida. }\end{array}$ \\
\hline
\end{tabular}




\begin{tabular}{|l|l|}
\hline Esperanza Romero & $\begin{array}{l}\text { ¿Por qué soy periodista? Siempre he sido intolerante a la injusticia. Soy de las } \\
\text { que brincan ante los impositivos y ante los que oprimen. Soy de las que piden } \\
\text { explicaciones ante los actos de corrupción. Me gusta denunciarlos y evidenciar } \\
\text { los excesos. He sido amenazada, pero mi compromiso es mayor. Los periodistas } \\
\text { de investigaciones especiales, siempre vamos a documentar e investigar. Yo he } \\
\text { cuidado mi credibilidad y mi nombre, porque al final de cuentas eres el respon- } \\
\text { sable de lo que escribes. Se debe trabajar con rigor y reportear en el lugar de los } \\
\text { hechos. }\end{array}$ \\
\hline Yolanda Zamora & $\begin{array}{l}\text { Cuando iba a la escuela me encantaba, a la hora del recreo, empezar a contarles } \\
\text { historias a mis amigas. Y ellas me rodeaban, escuchaban atentas. Yo inventaba } \\
\text { todo y pese a ello, les gustaba escucharme. Desde entonces la palabra fue mi } \\
\text { mejor herramienta. Seguramente por eso todavia cuento historias, ahora en la } \\
\text { radio. Siempre he trabajado temas relacionados con la cultura, entrevisto, hago } \\
\text { reseñas y doy comentarios. }\end{array}$ \\
\hline
\end{tabular}

Fuente: Creación propia, 2021.

De igual manera, detallaron la forma de organizar su día a día, donde mostraron su disciplina y compromiso para cumplir con la empresa periodística que publicará sus trabajos. Se advierte la forma en que oscilan entre lo público y lo privado, la labor periodística y las tareas del hogar, su rol como mujeres periodistas y como esposas y/o madres.

Cuadro 2.

Rutina laboral en sus periódicos

\begin{tabular}{|l|l|}
\hline Periodista & Testimonio \\
\hline Rosario Bareño & $\begin{array}{l}\text { Me voy a cubrir mi fuente, averiguas lo que se maneja, consigues datos, haces } \\
\text { sondeos, preguntas y niegan, preguntas y explican, vas de un lado a otro, buscan- } \\
\text { do la declaración, la nota, pero ningún día es igual. Mi jornada es rara porque } \\
\text { trabajo todos los días, el domingo soy la responsable de la edición del periódico, } \\
\text { pero cuando puedo voy al cine, voy a cumplir } 20 \text { años de casada y pese a todo le } \\
\text { hemos apostado a nuestra relación. Mis hijos van haciendo su vida, aunque cada } \\
\text { que puedo me quedo con ellos. Pero siempre, cada día, surge y se mantiene la } \\
\text { vocación de escribir, de seguir haciendo periodismo. }\end{array}$ \\
\hline Daniela Geomar & $\begin{array}{l}\text { Te vas especializando y ya se te hace más fácil. Lees la historia del equipo, su } \\
\text { trayectoria, distingues a sus mejores jugadores, reconoces en qué posición juega } \\
\text { y lo que significa ser un delantero o lateral, las reglas de ese deporte. Por eso, ya } \\
\text { después iba yo al estadio a reportear a cualquier equipo de Jalisco e identificaba } \\
\text { la alineación, los movimientos en la cancha, el gol como la emoción suprema de } \\
\text { este deporte. Podía ir a los entrenamientos para preguntar lo que esperaban del } \\
\text { próximo partido, qué características tenía el próximo rival, los puntos de diferen- } \\
\text { cia, el lugar en la tabla de posiciones, los resultados que antes habian tenido y si } \\
\text { era un equipo que había sido un rival difícil o no. }\end{array}$ \\
\hline
\end{tabular}




\begin{tabular}{|c|c|}
\hline Laura Castro & $\begin{array}{l}\text { En } 2005 \text { renuncié a ser reportera y me quedé nada más con mi columna. Me hice } \\
\text { supervisora y jefa de redacción ya en Guadalajara otra vez, entonces me encontré } \\
\text { con la radio. Fui conductora y productora de "Buenas noches metrópoli". Fue en } \\
\text { ese entonces que integré el concepto de periodismo ćvico. Los periodistas ćivicos } \\
\text { creen que es posible brindar una cobertura noticiosa que motive a las personas a } \\
\text { pensar e incluso a actuar, más que simplemente atraerlas a mirar. Y creen que } \\
\text { tienen la responsabilidad de hacerlo así. Pero, el } 11 \text { de octubre de } 2013 \text { me dicen } \\
\text { que estoy despedida. Yo miraba a mi jefe y le preguntaba: ¿Por qué, por qué me } \\
\text { corres? Me quitaron mi espacio y me dolió mucho. Lo más triste es que nadie } \\
\text { reclamó ni me defendió. Fue un golpe muy duro. Sin embargo, pese a mi dolor, } \\
\text { repetí:Yo no me voy a callar. Y aqú sigo. }\end{array}$ \\
\hline Priscila Hernández & $\begin{array}{l}\text { Yo hacía mis notas, preguntaba, investigaba, entrevistaba, toda mi información } \\
\text { ganada por mi trabajo. A veces le proponía temas a mi jefe. No me conformaba } \\
\text { con hacer una nota o dos, a veces presentaba una crónica o pedía tiempo para } \\
\text { hacer mejor un reportaje. Al editor le encantaba que llegara con temas frescos, } \\
\text { con una mirada diferente, eso, eso me gusta que hagas, me decía, no te quedes en } \\
\text { la superficie, pregunta, averigua, escarba, ve siempre un poco más allá y un poco } \\
\text { más. }\end{array}$ \\
\hline Vanesa Robles & $\begin{array}{l}\text { Yo hago mis crónicas siempre viendo lo que otros no ven, segura de que yo no } \\
\text { soy el centro de la historia, la verdad, soy una desorganizada, pero entre mi caos } \\
\text { el compromiso lo ordena. Salgo cada día a reportear siempre con una mirada } \\
\text { ingenua para sorprenderme de lo que yo misma veo. No escribo mientras algo no } \\
\text { me cause una emoción. Me parece que es muy difícil pasar esa emoción a los lec- } \\
\text { tores, si no la siente el periodista. No uso grabadora, casi nunca, excepto cuando } \\
\text { sé que hay cosas que se me van a ir porque la charla con alguna de las personas } \\
\text { es muy larga y con muchos datos. Enseguida si siento algo, si me emociono con } \\
\text { algo intento pasarlo rapidísimo para que no se me olvide, para que permeé todo } \\
\text { el texto esa emoción. Yo creo que, en el caso de la crónica, es muy importante } \\
\text { escribir lo que viste lo más pronto posible. }\end{array}$ \\
\hline Esperanza Romero & $\begin{array}{l}\text { Me defino como una incansable reportera que se da tiempo para dejar el escri- } \\
\text { torio y levantarte, empolvarte y caminar, buscar, tocar puertas, no cesar hasta } \\
\text { encontrar el testimonio, el dato, la prueba, el documento que sostenga tu inves- } \\
\text { tigación periodística. Esto es lo que me ha funcionado, asi es como me he hecho } \\
\text { de una agenda de contactos y fuentes confiables y también he establecido una } \\
\text { metodología. Hay quienes te dicen cómo debes escribir, cómo debes entrar, el desa- } \\
\text { rrollo y remate. Yo armo la rompecabeza y mientras estoy en la parte de recabar } \\
\text { información y de reunir las piezas, no me caso con ninguna idea y no armo la } \\
\text { nota por así decir, porque siempre estoy esperando que voy a encontrar algo más } \\
\text { y tiendo a no ponerle el limite porque eso sí, no me canso de reportear. }\end{array}$ \\
\hline
\end{tabular}




\begin{tabular}{|l|l|}
\hline Yolanda Zamora & $\begin{array}{l}\text { Me dice el director: "quiero que hagas un programa como tú lo diseñes, te lo me- } \\
\text { reces. Elije cómo quieres trabajarlo". Decidí hacer un programa en vivo, diario, } \\
\text { pero profundo con sello cultural. Por supuesto, a mi querido director no le pareció } \\
\text { tan maravillo: "Yolanda, no hay programa cultural que resista una hora". Oh } \\
\text { y ya llevo } 30 \text { años en esto. No fue magia ni suerte, fue trabajo. Simplemente me } \\
\text { empecé a rodear de gente comprometida, culta y sencilla, con ganas de compartir. } \\
\text { Doy notas sobre cultura y después quienes colaboran conmigo, sin ningún sueldo, } \\
\text { pero siempre con mucho compromiso, redondean cada tema abordado. }\end{array}$ \\
\hline
\end{tabular}

Fuente: Creación propia, 2021.

Finalmente, advierten que, si bien su compromiso y esfuerzo son significativos, el deber ser puede limitarlas, provocar más exigencia consigo mismas y crear estrategias para cumplir con su rol de esposas y, sobre todo, de madres de familia. En este punto, destaco los tres aspectos que Alberti (1996) indicaba al hacer estudio de oralidad con perspectiva de género:

1. Las siete periodistas muestran como característica común su apuesta por el cambio, una total iniciativa de salir de lugares comunes y confrontar situaciones con las que no estaban de acuerdo. Sus testimonios se enmarcan en la cotidianidad, comprometidas con su espacio laboral, pero atentas a su escenario privado en casa. Pero, de igual forma cuestionan y transforman el deber ser para fortalecer su trayectoria con el ser de periodistas.

Cuadro 3.

Ser mujer periodista.

\begin{tabular}{|l|l|}
\hline Periodista & Testimonio \\
\hline Rosario Bareño & $\begin{array}{l}\text { Lo confieso, ya no puedo trabajar como la hacía antes, ahora soy madre y bajé } \\
\text { un poco de ritmo, bajé mi forma de trabajar porque tenía a mis hijos chicos, pero } \\
\text { siempre cumpli con cada nota que me tocaba hacer. Hoy, en estos momentos, es } \\
\text { cuando estoy disfrutando más el trabajo. Soy sincera, retomo mi ritmo de los } \\
\text { inicios porque mis hijos ya son adolescentes, ya los puedo dejar, llamarles para } \\
\text { checar que están bien mientras yo discuto en la redacción una entrada o en enca- } \\
\text { bezado. Ya voy para treinta años de trayectoria profesional, y he visto como nos } \\
\text { vamos organizando para cumplir en los campos que las mujeres queremos estar. } \\
\text { Sin embargo, también observo que llegamos, pero solamente para reportear, hay } \\
\text { muy pocas jefas de información, sí, yo fui la primera, pero no han surgido más. }\end{array}$ \\
\hline Daniela Geomar & $\begin{array}{l}\text { Yo no soy feminista, pero estoy segura que la ropa no da pauta para que te advier- } \\
\text { tan que, si no cuidas tu manera de vestir, no podrán contratarte. Me acuerdo que } \\
\text { en un periódico me dijeron: "ahorita como vienes de invitada, no podemos decirte } \\
\text { nada, pero ya trabajando aqú, solamente falda, nunca minifalda". Me pareció } \\
\text { muy injusto, me pregunté dónde está la equidad, los derechos. ¿No vale más mi ta- } \\
\text { lento que mi manera de vestir? Nunca olvido esa advertencia: "Cuando trabajes en } \\
\text { el periódico tienes que andar de falda, porque asi andan las mujeres de verdad... } \\
\text { ¿Tienes algún conflicto con ello? Musité un "no" bajito... Ah bueno, respondieron, } \\
\text { perfecto, te esperamos". }\end{array}$ \\
\hline
\end{tabular}




\begin{tabular}{|c|c|}
\hline Laura Castro & $\begin{array}{l}\text { En } 1989 \text { entro al periódico más antiguo y más importante del estado: "El Informa- } \\
\text { dor". Sí, ya sé la mala fama que le han hecho, de que no les gusta tener mujeres } \\
\text { trabajando en su redacción, que te prohíben trabajar con pantalón, que te arrin- } \\
\text { conan a las fuentes de sociales. Pero eso nunca me afectó, yo impuse mi trabajo y } \\
\text { mi compromiso. Es cierto, una vez me regresaron a mi casa por usar minifalda, } \\
\text { pero también otras veces fueron respetuosos y hasta protectores conmigo. Pero si yo } \\
\text { detectaba diferencias que provocan desigualdades, las denunciaba. No me queda- } \\
\text { ba callada. En ese entonces era la única reportera en el diario. Quizá por eso la } \\
\text { discriminación era más sutil, pero existía. Yo reporteaba el doble de bien y por eso } \\
\text { me empezaron a respetar. }\end{array}$ \\
\hline Priscila Hernández & $\begin{array}{l}\text { Me sorprende e indigna cuando algunas periodistas aceptan condiciones que afec- } \\
\text { tan sus posibilidades de vivir en una sociedad equitativa. Ya sabes, esa historia de } \\
\text { diarios como "El Informador" que para entrar te piden examen médico para checar } \\
\text { que no estás embarazada. A un compañero hombre nunca le preguntan cuántos } \\
\text { hijos tiene, pero a una candidata a ser reportera, la interrogan sobre el número } \\
\text { de hijos, que cómo se va a organizar para cumplir su rol de madre. Lo de no usar } \\
\text { pantalón, la falda guardada en la bolsa y antes de llegar al periódico plancharla } \\
\text { con las manos y a ponértela. Esto indigna desde una postura no solamente femi- } \\
\text { nista, sino de simples derechos humanos, pero no lo han interiorizado. Te dicen } \\
\text { que no importa ser hombre o mujer, si no trabajar con profesionalismo, pero no } \\
\text { reconocen que estamos en un sistema que genera desigualdad, que no nos pone en } \\
\text { las mismas condiciones, que nos dan años luz de desventaja. }\end{array}$ \\
\hline Vanesa Robles & $\begin{array}{l}\text { Ser periodista es un privilegio en la escala social, la neta. Fui mamá a los } 29 \text { años } \\
\text { y luego a los } 38 \text {. He amado y me han amado. Como buena madre, tengo problemas } \\
\text { con mi hija pre adolescente, ya se fue a vivir a otro lado. Ahora con Matías me } \\
\text { organizo mejor. Intento cumplir ese rol. El otro día, estaba con mi psicóloga y no } \\
\text { tenía donde dejar a Matías y me lo llevé. Se quedó en la terapia, cré que no iba a } \\
\text { poner atención, en eso le digo a mi doctora que siento culpa. Matías voltea y me } \\
\text { dice; jNo digas esa palabra mamá, esa palabra no debería existir, la culpa! Y tiene } \\
\text { cinco años, creo que entiende mejor mucho más las cosas que yo. Y así ando, de } \\
\text { tesista, maestra, mamá, mujer, amiga, cronista, periodista, con culpas y retos, con } \\
\text { culpas y seguridades, mientras mi hijo me insiste en que la culpa es una palabra } \\
\text { prohibida en mi diccionario. }\end{array}$ \\
\hline Esperanza Romero & $\begin{array}{l}\text { Yo vivo en una sociedad que me enseñó que mi función primordial es la de ser ma- } \\
\text { dre y esposa, pero siempre trato de compaginarla con el periodismo. Para lograrlo, } \\
\text { sigo publicando, pero porque trabajo como freelance. Intenté ser editora pero no me } \\
\text { llenaba tanto como estar en el lugar de la noticia. Quiero seguir siendo reportera, } \\
\text { pero sin dejar mis tareas de madre y esposa. Ahora también doy clases. He tenido } \\
\text { que bajar el ritmo, pero nunca dejaré la investigación periodística. }\end{array}$ \\
\hline
\end{tabular}




\begin{tabular}{|l|l|}
\hline Yolanda Zamora & $\begin{array}{l}\text { A estas alturas del partido te puedo decir que vivo con una gran plenitud y no } \\
\text { desaprovecho el tiempo. Yolanda Zamora vive lo que quiere vivir, tengo el privile- } \\
\text { gio de ser madre, tener pareja, ser una profesional de la comunicación, escritora y } \\
\text { maestra. Muchas facetas me enriquecen porque el mundo no es vertical, es hori- } \\
\text { zontal, entonces me he expresado en diferentes campos con gran plenitud. Yo no } \\
\text { niego una serie de problemáticas que se viven lamentablemente en nuestro país, } \\
\text { pero creo profundamente que podemos convivir con iniciativas de campo impor- } \\
\text { tantes, no porque uno vaya a redimir al mundo, pero siempre hay posibilidades de } \\
\text { sembrar semilla de buena fe que tarde o temprano darán el fruto deseado. }\end{array}$ \\
\hline
\end{tabular}

Fuente: Creación propia, 2021.

Los tres temas que guiaron la charla con las siente periodistas, las respuestas de cada una y la perspectiva de género, permiten interpretar la construcción de género latente en su ser periodista que complica su desarrollo profesional, pero al mismo tiempo, algunas de ellas han reconocido la forma de no dejar de ser periodistas.

Cuadro 4.

Perspectiva Género y el ser mujer periodista.

\begin{tabular}{|l|l|}
\hline $\begin{array}{l}\text { Elementos de la cons- } \\
\text { trucción de género }\end{array}$ & Interpretación \\
\hline Mitos y símbolos. & $\begin{array}{l}\text { Por qué son periodistas. Reconocen la vocación y la influencia de } \\
\text { ejemplos retomados de los medios o de sus profesoras. } \\
\text { Rutina laboral en sus periódicos. Se impone el rol de la reportera sin } \\
\text { horario, pero también la culpa para cumplir con su papel de madres. } \\
\text { Ser mujer periodista. La maternidad ha sido definitiva para que sien- } \\
\text { tan dificultades en su realización. } \\
\text { Muestran una actitud de cambio, entremezclan lo privado con lo } \\
\text { público y observan la diferencia entre el deber ser y el ser. }\end{array}$ \\
\hline Conceptos normativos. & $\begin{array}{l}\text { Por qué son periodistas. Lograron prepararse en la universidad, pero } \\
\text { tuvieron que hacer acuerdos o ceder con algunas políticas de sus perió- } \\
\text { dicos. } \\
\text { Rutina laboral en sus periódicos. Prefirieron trabajar de manera } \\
\text { independiente ante la imposibilidad de acordar con sus empresas perio- } \\
\text { dísticas. } \\
\text { Ser mujer periodista. Reconocen que deben trabajar el doble de bien } \\
\text { para que la empresa tenga un trato respetuoso y de equidad con ellas. } \\
\text { Muestran una actitud de cambio, entremezclan lo privado con lo } \\
\text { público y observan la diferencia entre el deber ser y el ser. }\end{array}$ \\
\hline
\end{tabular}




\begin{tabular}{|l|l|}
\hline $\begin{array}{l}\text { Nociones políticas y } \\
\text { referencias a las institu- } \\
\text { ciones y organizaciones } \\
\text { sociales. }\end{array}$ & $\begin{array}{l}\text { Por qué son periodistas. Han recibido apoyo de la familia, lograron } \\
\text { elegir libremente su carrera profesional, pero el rol de esposa y madre } \\
\text { les impide estar a la par de las exigencias de la empresa donde laboran. } \\
\text { Rutina laboral en sus periódicos. Han tenido que enfrentar la doble } \\
\text { y triple jornada laboral, sin lograr equilibrar la familia y el trabajo en su } \\
\text { medio de comunicación. } \\
\text { Ser mujer periodista. Advierten que viven una situación diferente a la } \\
\text { de sus compañeros, donde a ellas el rol asignado por la sociedad no les } \\
\text { permite trabajar y hasta competir al mismo ritmo, por lo que reconocen } \\
\text { el doble esfuerzo para continuar su vida en el periodismo. } \\
\text { Muestran una actitud de cambio, entremezclan lo privado con lo } \\
\text { público y observan la diferencia entre el deber ser y el ser. }\end{array}$ \\
\hline $\begin{array}{l}\text { Por qué son periodistas. Identificaron su vocación, comprobaron que } \\
\text { tienen talentos y herramientas necesarias para reportear. } \\
\text { Rutina laboral en sus periódicos. Han creado sus propias estrategias, } \\
\text { principalmente ser trabajadores independientes, para continuar repor- } \\
\text { teando. } \\
\text { Ser mujer periodista. La vocación, el compromiso y los reconoci- } \\
\text { mientos fortalecen su decisión de ser periodistas. } \\
\text { Determinante para el cambio, representativa para moverse entre lo } \\
\text { privado y lo público, definitiva para romper con el deber ser y atre- } \\
\text { verse al ser. }\end{array}$ \\
\hline
\end{tabular}

Fuente: Creación propia, 2021.

\section{Conclusiones}

¿Quiénes son las mujeres periodistas en Guadalajara y cómo realizan su labor periodística? Fue la pregunta que permitió explorar el periodismo de la región y buscar a las mujeres que lo ejercen. Fue así como, a través de sus testimonios, logré advertir las cuestiones de género que ellas enfrentan al vivir su oficio periodístico:

Su decisión de ser periodista. Una gran libertad en su elección, donde su vocación ya viene formándose desde su niñez y la certeza de que es una profesión que pueden ellas ejercer sin ninguna limitación. Dominan cualquier género periodístico, aunque cada una mostró preferencia por alguno en especial. El contexto parece marcar las posibilidades e imposibilidades para que se les asigne una fuente. Mientras Rosario Bareño tuvo que ganarse a pulso cubrir una fuente que no fuera considerada tradicional para las mujeres, como los son sociales y asistenciales, Daniela Geomar tuvo el apoyo para entrar a deportes y su juventud fue razón para ser protegida por sus compañeros y Esperanza Romero ha destacado por su fuerte carácter y gran trayectoria. En tanto Laura, Priscilla y Vanesa, que se convirtieron en periodistas en años más recientes, ya no se preocuparon de lograr entrar a un medio, pero se han sentido relegadas.

La jornada laboral. Ser mujeres puede complicar su horario de trabajo, los hijos pueden limitarlas para dedicarse totalmente a reportear, quizá por eso dos de ellas han decidido no tenerlos. Sin 
embargo, crean sus propias estrategias, principalmente bajar el ritmo, esperar a que los hijos crezcan o ser trabajadoras independientes para no estar en la sala de redacción o en un horario más libre.

Hallazgos en la oralidad y género. Los testimonios observados reafirman lo que Alberti (1996) distinguía en la aplicación de los estudios de oralidad y la antropología de género: En el lenguaje coloquial de las periodistas a lo largo de las entrevistas se advierte un reconocimiento por el cambio, la entremezcla entre lo público y lo privado que alcanza sentido en este contexto, y la forma en que manifiestan sin victimizarse las diferencias entre el deber ser y el ser, buscando estrategias para ser las periodistas y mujeres que desean ser. Por ello, reitero y procuro continuar la advertencia de Alberti (1996):

El contexto marca el valor del testimonio, el momento histórico, la clase social, la edad, la etnia y el género van a determinar la forma de asimilar las experiencias. Todos son ejes que se presentan en la realidad como un todo. Es en el análisis teórico cuando se separan para abarcar el cúmulo de datos. Sin embargo, el eje de género ha sido poco estudiado. Se necesita un método, una teoría, una voluntad y una conciencia para aplicarlo, no se da de forma espontánea al hablar de las mujeres. Por eso los datos recogidos desde la perspectiva de género resultan sumamente valiosos para reconstruir la vida de las mujeres y de los hombres desde otra mirada, y enriquecer el acervo teórico de la Antropología de género, así como de la Historia Oral. (Alberti, 1996, p. 15)
Ser mujer periodista. Cada una advirtió la falta de apoyo que a veces tienen de la empresa para la que trabajan, a veces no hay reconocimiento o parece ser más difícil que como mujeres puedan tener un mejor puesto o una de dirección. Advierten que siguen siendo pocas mujeres y que en algunas empresas la discriminación de género está latente. Advierten que todavía hay fuentes que por ser mujeres no pueden cubrir pero que por esfuerzo personal poco a poco logran acceder. 


\section{Referencias}

Alberti Manzanares, P. (1996). Historia oral y antropología de género. Boletín americanista, N.46, España, pp.7-17.

Cano, G. \& Radku. V. (1986). Lo privado y lo público o la mutación de espacios. Historia de Mujeres 1920 - 1940. La investigación sobre la mujer: informes en sus primeras versiones, México: El Colegio de México, pp. 514 - 561 .

Cazés, D. (1998). La perspectiva de género. Guía para diseñar, poner en marcha, dar seguimiento $y$ evaluar proyectos de investigación y acciones públicas y civiles. México: Consejo Nacional de Población.

Herrero Morales, L. \& Orozco, T. (1991). Vida cotidiana y quehacer social de las mujeres periodistas en Guadalajara (El caso de las reporteras de cinco diarios matutinos: El diario, El Jalisciense, El Informador, El occidental y Ocho columnas). México: Universidad de Guadalajara.

Scott, J. W. (2015). El género: una categoría útil para el análisis histórico. El género: una categoría útil para el análisis histórico, 251-290. 